\title{
Distance versus near visual acuity in amblyopia
}

\author{
Alex Christoff, $\mathrm{CO}^{\mathrm{a}}$, Michael X. Repka, MD, MBA ${ }^{\mathrm{a}, \mathrm{b}}$, Brett M. Kaminski ${ }^{\mathrm{b}}$, Jonathan M. \\ Holmes, BM, and B Ch ${ }^{\mathrm{c},}{ }^{*}$ on behalf of the Pediatric Eye Disease Investigator Group \\ aZanvyl Krieger Children's Eye Care Center, The Wilmer Ophthalmological Institute, Johns \\ Hopkins Hospital, Baltimore, MD \\ bJaeb Center for Health Research, Tampa, FL \\ 'Department of Ophthalmology, Mayo Clinic, Rochester, MN
}

\begin{abstract}
Purpose-There are conflicting reports about whether distance and near visual acuity are similar in eyes with amblyopia. The purpose of this study is to compare monocular distance visual acuity with near visual acuity in amblyopic eyes of children.
\end{abstract}

Methods-Subjects 2 to 6 years of age were evaluated in a randomized trial of amblyopia therapy for moderate amblyopia (20/40 to 20/80) due to anisometropia, strabismus, or both. Prior to initiating the protocol-prescribed therapy, subjects had best-corrected visual acuity measured with standardized protocols at 3 meters and 0.4 meters using single-surrounded HOTV optotypes.

Results-A total of 129 subjects were included. The mean amblyopic eye visual acuity was similar at distance and near (mean, $0.45 \log \mathrm{MAR}$ at distance versus $0.45 \log \mathrm{MAR}$ at near; mean difference, $+0.00,95 \% \mathrm{CI},-0.03$ to 0.03$)$. Of the 129 subjects, $86(67 \%)$ tested within one line at distance and near, 19 (15\%) tested more than one logMAR line better at distance, and 24 (19\%) tested more than one $\log$ MAR line better at near. The mean visual acuity difference between distance and near did not differ by cause of amblyopia, age, or spherical equivalent refractive error.

Conclusions-We found no systematic difference between distance and near visual acuity in 2to 6-year-old children with moderate amblyopia associated with strabismus and/or anisometropia. Individual differences between distance and near visual acuity are likely due to test-retest variability.

\section{Introduction}

Based on principles of geometrical optics, it is expected that visual acuity would be the same at distance and near. However, reports of visual acuity of amblyopic eyes have found that visual acuity at near differs compared to visual acuity at distance. ${ }^{1-3}$ Some authors have

\footnotetext{
(C) 2011 American Association for Pediatric Ophthalmology and Strabismus. Published by Mosby, Inc. All rights reserved. Corresponding author: Michael Repka, MD, MBA c/o Jaeb Center for Health Research, 15310 Amberly Drive, Suite 350, Tampa, FL 33647 (pedig@jaeb.org).

The members of the Pediatric Eye Disease Investigator Group participating in this study are provided in e-Supplement 1, available at jaapos.org.

This study is registered as NCT 00094614 at www.clinicaltrials.gov.

The authors have no financial or conflicting interests in the subject of this report to disclose.

Publisher's Disclaimer: This is a PDF file of an unedited manuscript that has been accepted for publication. As a service to our customers we are providing this early version of the manuscript. The manuscript will undergo copyediting, typesetting, and review of the resulting proof before it is published in its final citable form. Please note that during the production process errors may be discovered which could affect the content, and all legal disclaimers that apply to the journal pertain.
} 
speculated that amblyopic eyes with reduced visual acuity at near have reduced accommodation. ${ }^{4-6}$ The purpose of the present study was to compare the monocular visual acuity of amblyopic eyes measured at 3 meters and 0.4 meters, using standardized protocols, in subjects with moderate amblyopia less than 7 years old.

\section{Methods}

The subjects for this study participated in A Randomized Trial of Atropine Regimens for Treatment of Moderate Amblyopia in Children conducted by the Pediatric Eye Disease Investigator Group (PEDIG) and registered as NCT 00094614 at www.clinicaltrials.gov. ${ }^{7}$ The protocol and HIPAA compliant informed consent forms were approved by institutional review boards, a parent or guardian of each study subject gave written informed consent, and subjects gave assent as required. The study was designed to compare daily atropine to weekend atropine after 4 months of treatment in children $<7$ years of age with moderate amblyopia, defined as distance visual acuity of $20 / 40$ to $20 / 80$. Subjects were excluded if they had amblyopia of indeterminate cause $(n=4)$ or if they were enrolled prior to the addition of the near test to the study protocol $(\mathrm{n}=35)$. The full protocol is available on the PEDIG Web site (www.pedig.net) and is summarized below.

Baseline testing included measurement of distance visual acuity by a study-certified vision tester using the ATS VA-testing protocol. ${ }^{8}$ The ATS testing protocol was presented on the electronic visual acuity tester, ${ }^{9}$ showing single surrounded HOTV optotypes ranging from $20 / 800$ to 20/16 at 3 meters. The near acuity test consisted of a series of flip cards with single-surrounded HOTV optotypes, beginning at 20/400 and ending at 20/20 in 0.1 $\log$ MAR intervals at $40 \mathrm{~cm}$ controlled with a measuring cord (ATS4 Near Acuity Test, Precision Vision, Chicago, IL, Catalog \#2053). The visual acuity testing protocols have been published. ${ }^{7}$ A matching card of the optotypes was used for both distance and near testing. Spectacles were worn, if prescribed. The protocol for correction of refractive error has also been published. ${ }^{10}$ Distance visual acuity was tested before near visual acuity in all subjects.

\section{Statistical Methods}

Distance visual acuity scores of 20/16 were designated 20/20 for analysis. This reduced the effect of different visual acuity ceilings for each test. Visual acuity measures were converted to $\log$ MAR (logarithm of the minimum angle of resolution) scores for analysis. To be included in the analysis, subjects had to have both near and distance acuities measured in the amblyopic eye.

The difference between distance and near visual acuity was evaluated using a paired $t$ test, and a 95\% confidence interval for the difference was calculated. Linear regression was used to determine whether cause of amblyopia, age, and spherical equivalent refractive error in the amblyopic eye were associated with the difference between distance and near scores. The Tukey-Kramer adjustment for multiple comparisons was used for the cause of amblyopia subgroup comparisons.

To compare our results to prior studies, visual acuity measures from the prior studies were converted to $\log \mathrm{MAR}$, with visual acuity scores that were worse than the testing scale (eg, $<20 / 400$ ) imputed as one line worse (eg, 20/500). Mean differences and 95\% confidence intervals were then estimated using the data reported. All analyses were performed using SAS version 9.1 (SAS Institute, Cary, NC). 


\section{Results}

A total of 168 patients were enrolled. Of these, 129 met inclusion criteria for the present analysis. Patient and eye characteristics for the 129 subjects are summarized in eSupplement 2 (available at jaapos.org). Mean age was $5.3 \pm 1.1$ years (range, 2.4 to 6.9 years). Subjects included in the analyses were similar to those who were not included ( $\mathrm{n}=$ 39 ) with respect to age, refractive error, and distance visual acuity.

Mean distance visual acuity in the amblyopic eye was $0.45 \pm 0.11 \log$ MAR and mean near visual acuity was $0.45 \pm 0.21 \log$ MAR. Of the 129 subjects, $86(67 \%)$ subjects tested within one $\log$ MAR line at distance and near, $19(15 \%)$ tested more than one logMAR line better at distance, and $24(19 \%)$ tested more than one logMAR line better at near (Table 1). The mean amblyopic eye visual acuity did not differ by testing distance (mean difference, 0.00 $\log$ MAR [ $95 \% \mathrm{CI},-0.03$ to $0.03 \log \mathrm{MAR}$ ]; Figure 1 ). The mean acuity difference did not differ by cause of amblyopia, age or spherical equivalent refractive error (Table 1).

\section{Discussion}

We compared near and distance visual acuities of subjects 2 to 6 years of age with moderate amblyopia from strabismus, anisometropia or both combined, by using standardized visual acuity testing protocols at distance and near with single surrounded HOTV optotypes. Near visual acuity of amblyopic eyes did not differ from distance visual acuity. The fact that the distance and near testing protocols were not identical could be considered a limitation of the study. The near test included no reinforcement phase or second threshold phase, which were part of the distance testing protocol. Nevertheless, we did not find any difference comparing near and distance visual acuity. The difference in variability between distance and near visual acuity was not examined since the distribution of distance scores was constrained by the eligibility criteria.

Our findings differ from earlier reports regarding near visual acuity in amblyopic eyes. Catford ${ }^{1}$ found that 18 of 35 hypermetropic amblyopic subjects (51\%) had worse visual acuity of the amblyopic eye at near, whereas $5(14 \%)$ were better at near. Von Noorden and Helveston ${ }^{2}$ found that 9 of 46 esotropic amblyopic subjects (19\%) had worse visual acuity of the amblyopic eye at near, whereas $17(37 \%)$ were better at near. Lennarson and colleagues $^{3}$ studied 70 patients with amblyopia from strabismus, anisometropia, or both, as in our study, and found that 33 of 70 subjects (48\%) had worse visual acuity of the amblyopic eye at near, whereas $8(11 \%)$ were better at near. All three studies of amblyopic children found a substantial proportion of subjects with no difference between distance and near visual acuity. ${ }^{1-3}$ We calculated mean values for the distance minus near visual acuity difference for each of these studies: Catford, ${ }^{1}-0.07(-0.14,-0.004)$; Von Noorden and Helveston, ${ }^{2} 0.03$ (-0.03, 0.09); Lennarson and colleagues, ${ }^{3}-0.08(-0.11,-0.05)$; the first and last of these studies noted slightly poorer near visual acuity in the amblyopic eye.

We do not include analyses of fellow eyes because the near-testing protocol created a ceiling effect at 20/20 since near visual acuity better than 20/20 could not be measured. Therefore, subjects testing at or near 20/20 at distance in the fellow eye were constrained with respect to how much better they could test at near, introducing a bias into any observed differences, and in fact $55(43 \%)$ of fellow eyes tested 20/20 at near. Also, the limitations on the range in distance visual acuity imposed by eligibility criteria precluded use of standard Bland-Altman methods ${ }^{10}$ for comparing distance and near acuities, as these methods assume no constraints on either measurement. However, we believe these issues introduced minimal bias in our evaluation of amblyopic eyes, because we observed minimal ceiling effect with only 2 amblyopic eyes with 20/20 (or possibly better) near visual acuity (Table 1), and minimal 
regression to the mean with relatively equal numbers of subjects testing better and worse at near within each level of distance visual acuity. Testing distance visual acuity first may introduce two offsetting biases. Some subjects may become fatigued and test more poorly on the second test, while others may experience a learning effect and test better.

We found no systematic difference between distance and near visual acuity in 2- to 6-yearold children with moderate anisometropic, strabismic, and combined amblyopia. Individual differences between distance and near visual acuity are likely due to test-retest variability.

\section{Supplementary Material}

Refer to Web version on PubMed Central for supplementary material.

\section{Acknowledgments}

Financial Support: Supported by the National Eye Institute of the National Institutes of Health, Department of Health and Human Services EY011751 and EY018810 and the Research to Prevent Blindness, Inc. New York, NY (JM Holmes as Olga Keith Weiss Scholar and an unrestricted grant to the Department of Ophthalmology, Mayo Clinic). The sponsor or funding organization had no role in the design or conduct of this research.

\section{References}

1. Catford GV. Amblyopia: A comparison between distance and near vision. Br J Ophthalmol. 1956; 40:633-5. [PubMed: 13374232]

2. von Noorden GK, Helveston EM. Influence of eye position on fixation behavior and visual acuity. Am J Ophthalmol. 1970; 70:199-204. [PubMed: 5455944]

3. Lennarson, LW.; France, TD.; Portnoy, J.; Scott, WE. A comparison of distance and near vision in amblyopia. Transactions V International Orthoptic Congress; Cannes, France. Oct 10-13, 1983; p. 329-6.

4. Guyton DL, O’Connor GM. Dynamic retinoscopy. Curr Opin Ophthalmol. 1991; 2:78-80. [PubMed: 10149292]

5. Abraham SV. Accommodation in the amblyopic eye. Am J Ophthalmol. 1961; 52:197-200. [PubMed: 13681091]

6. Hokoda SC, Ciuffreda KJ. Measurement of accommodative amplitude in amblyopia. Ophthal Physiol Opt. 1982; 2:205-12.

7. Pediatric Eye Disease Investigator Group. A randomized trial of atropine regimens for treatment of moderate amblyopia in children. Ophthalmology. 2004; 111:2076-85. [PubMed: 15522375]

8. Holmes JM, Beck RW, Repka MX, et al. The amblyopia treatment study visual acuity testing protocol. Arch Ophthalmol. 2001; 119:1345-53. [PubMed: 11545641]

9. Moke PS, Turpin AH, Beck RW, et al. Computerized method of visual acuity testing: Adaptation of the amblyopia treatment study visual acuity testing protocol. Am J Ophthalmol. 2001; 132:903-9. [PubMed: 11730656]

10. Pediatric Eye Disease Investigator Group. The clinical profile of moderate amblyopia in children younger than 7 years. Arch Ophthalmol. 2002; 120:281-7. [PubMed: 11879130] 


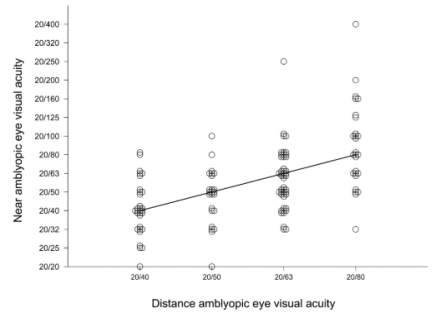

FIG 1.

Scatterplot of near versus distance visual acuity of the amblyopic eyes. 


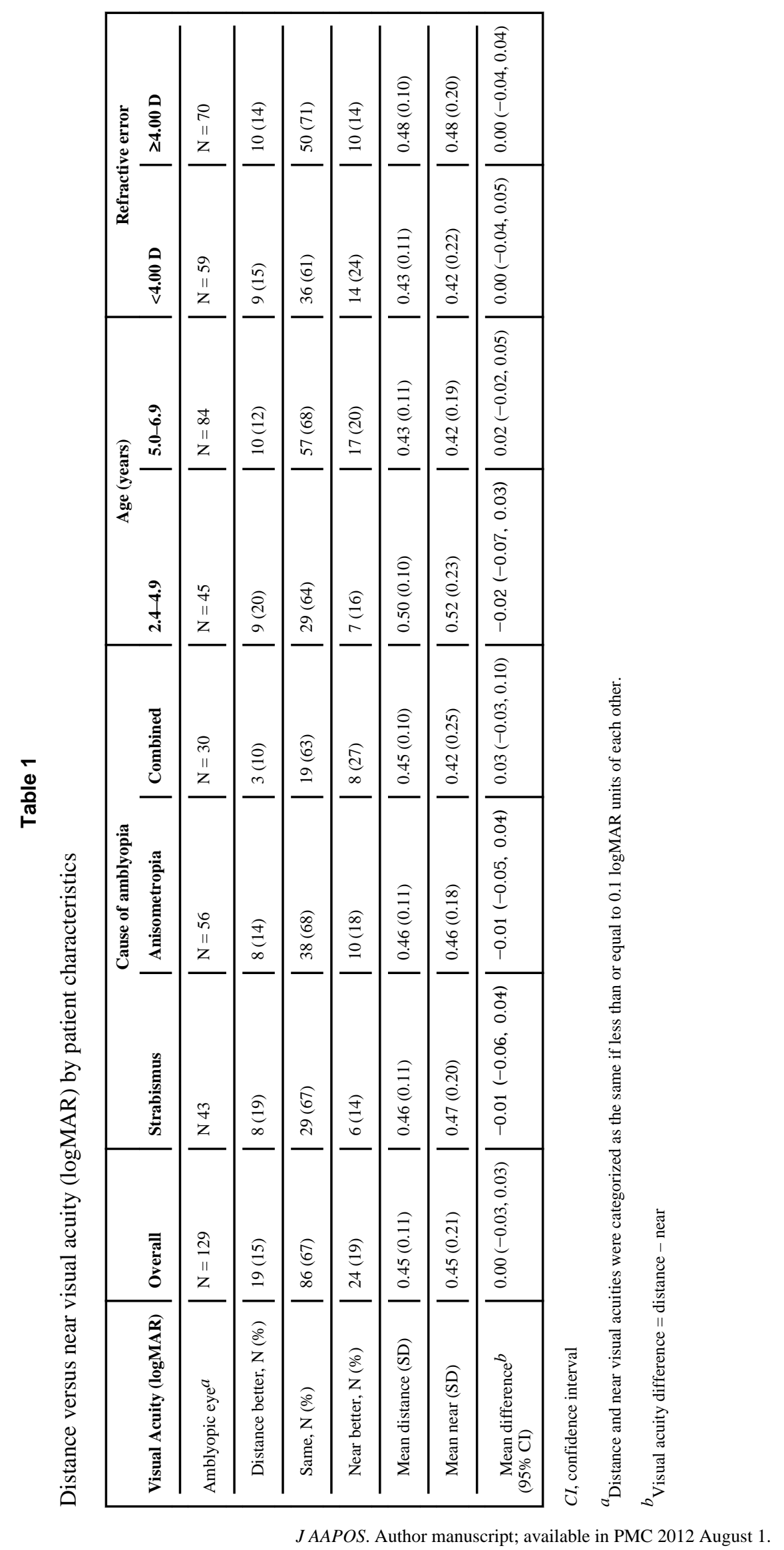

